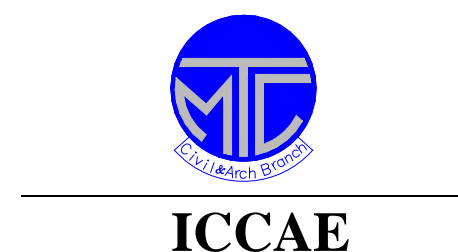

Military Technical College

Kobry Elkobbah, Cairo, Egypt 7th International Conference
On Civil \& Architecture
Engineering

\title{
INVESTIGATING THE EFFECT OF CURING TIME OF THE COLD IN PLACE RECYCLED ASPHALT MIXES ON THE LIFE CYCLE OF ASPHALT PAVEMENT
}

\author{
A. Mostafa ${ }^{*}$, K. Kandil ${ }^{* *}$, A. El-Desouky ${ }^{* * *}$, and A.O. Abd El Halim ${ }^{* * * *}$
}

\begin{abstract}
With escalating oil prices, pavement recycling is an attractive choice for road maintenance since it allows considerable savings as compared to new construction. It also mitigates environmental impacts, reduces the use of virgin materials, and minimizes transportation of materials off-site. Recycling of asphalt pavements is based on two different techniques: Hot In-place Recycling (HIR) and Cold In-place Recycling (CIR). Although CIR has significant advantages, the main disadvantage concerns the assessment of the CIR before being overlaid.

Several mix design are currently available for CIR mix design to optimize the water content and the emulsion for maximum strength. While the laboratory curing procedure for mix design purposes is defined, identifying the curing duration in the field is a primary concern. The main objective of this paper is to investigate the effect of the curing of the CIR on the life cycle of asphalt concrete pavement. An experimental program was designed to identify the relationship between the curing time and the modulus of elasticity. The output results of the experimental program were used in an analytical investigation to study the effect of the curing time on pavement lifecycle. The output results indicated that the curing time is a critical factor for controlling the long-term performance of asphalt concrete pavement.
\end{abstract}


Proceedings of the $7^{\text {th }}$ ICCAE Conf. 27 -29 May, 2008

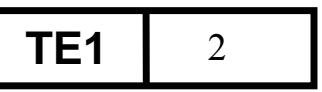

\section{KEY WORDS}

Cold In-place Recycling, Life Cycle, Asphalt Concrete Pavement, Modulus of Elasticity, Time Domain Deflectometer.

\subsection{INTRODUCTION}

There have been many advances in paving technology to economically address the common distress problems in asphalt pavements such as rutting, cracking and fatigue damage. The use of Reclaimed Asphalt Pavement (RAP) as a paving material through in-place or plant-produced processes is one of these advances, which has attracted significant interest in many countries. Specifically, it is estimated that pavement recycling can decrease road maintenance costs by half when compared to conventional methods [1]. In addition to the direct economic benefits, the development and refinement of processes that utilize reclaimed materials promotes environmental sustainability as the conventional paving technologies depend upon limited natural resources for aggregates and bitumen.

Conventional paving processes such as resurfacing or reconstruction require significant amounts of virgin materials and can generate a significant amount of RAP and/or soils that must be transported to another site for reprocessing or even disposal. Although this material may often be used again, in-place recycling can eliminate the need for off-site removal of materials, use less virgin aggregate and more old asphalt thereby saving resources, reducing material transportation needs, and requiring a lower total energy consumption [2].

The common concern about recycling is whether or not the quality and long-term performance of the pavements are being compromised. Current methods for the rehabilitation and reconstruction of asphalt pavements are based on two different techniques: Hot In-place Recycling (HIR) and Cold In-place Recycling (CIR). To address non-structural distresses such as oxidation, ravelling and fine cracking, HIR involves the heating and partial depth removal of the existing asphalt surface, mixing it with recycling agents and/or additional aggregate with the mix reapplied to the road in single or multiple layers [2]. Unless a subsequent layer of Hot Mix Asphalt (HMA) is placed over the HIR mix, no significant increase in pavement strength is observed.

On the other hand, CIR involves cold milling or pulverization of the existing asphalt pavement to address more deeply rooted distresses such as fatigue cracking and rutting. The reclaimed material is sized, mixed with small amounts of bitumen emulsion or expanded asphalt, placed and compacted. The term CIR is usually associated with the use of emulsion stabilization. Depending 


\subsection{OBJECTIVE}

Several mix design are currently available for CIR mix design, among this procedure is the modified Marshall procedure [1] to optimize the water content and the emulsion for maximum strength. While the laboratory curing procedure for mix design purposes is defined, identifying the curing duration in the field (thereby signalling the placement of the HMA overlay) is a primary concern. It should be noted that the placement of the HMA overlay before the right time would affect the life cycle of the constructed pavement. The main objective of this paper is to investigate the effect of the curing of the CIR on the life cycle of asphalt concrete pavement. This paper consists of three main parts. The first part presents an overview on the CIR process, the second part includes the experimental works, and the third part is the analytical investigation and conclusions.

\subsection{COLD IN-PLACE RECYCLING}

One of the main disadvantages of using CIR is the lack of available technical and performance data. The mechanical and material properties of CIR asphalt still require further investigations. It is, however, thought of as a good method of reducing thermal cracking [1]. CIR can be used to rehabilitate pavement with age cracking, thermal cracking, fatigue cracking, reflective cracking, and pavement deformation such as rutting, and shoving. In addition, it can be used to rehabilitate the loss of pavement integrity such as ravelling, flushing and the loss of bond between the layers.

CIR is a continuous process that involves the cold milling of existing pavement, screening, crushing, and mixing this material with a cold bituminous stabilizer, followed by laying the final product onto the roadway and compaction to suitable density. The material is allowed to cure, and then covered with a waterproof surface, usually HMA. Additives such as polymers, lime, cement, and fly ash can also be included. In many cases, alternative binders such as high-density emulsions and foamed asphalt have also been used [3]. Other researchers have carried out studies to identify suitable test methods that can be used to assess CIR mix properties. Among these, Rogge et al. [4] attempted to evaluate the CIR mix properties using the resilient modulus, fatigue, Marshall stability and flow, and Hveem stability tests. They reported that none of the aforementioned test methods was able to identify the optimum emulsion content for the mix design. Epps [5] recommended the use of the highest emulsion content that shows no bleeding while maintaining $4 \%$ air voids and Hveem stability of value of 30. Furthermore, Lee et al. [6] carried out a study to predict the performance of the CIR mixtures by conducting the performance tests such as incremental static dynamic creep, fatigue beams, and creep compliance. However, very limited results from these tests were reported. 
A recent development in CIR technology involves the use of expanded (foamed) asphalt rather than emulsified asphalt to bind the mix. In this new process, hot asphalt cement is pumped through an expansion chamber on the cold recycling unit, where a small amount (about 1 percent) of cold water is injected. This creates a large number of tiny bubbles within the hot asphalt cement causing it to rapidly expand (foam). The expanded asphalt is then mixed with the reclaimed asphalt pavement. As with conventional CIR, the material is then profiled and compacted to form a binder course layer. The major advantage of the use of expanded asphalt stabilization is that a new HMA surface can be applied following a two-day curing period if compaction requirements have been met. The process is therefore less dependent on warm, dry weather for placement, which may lead to an extended construction season [7].

It is well known that, Specifications are developed to encourage the construction of a road that will perform well. It seems likely that the current recipe specifications for CIR do not describe the wide range of mix designs and construction methods that would be necessary to construct roads that will perform well given the variety of conditions to which they are subjected. This leaves the following major challenges:

- There is no conformity concerning laboratory curing practices for CIR or expanded asphalt mixes.

- Realistic characterization of field properties by laboratory testing for these materials demands that laboratory processes must closely reflect field conditions, especially regarding, compaction of specimens, shape of the sample, and the process of the laboratory curing.

- $\quad$ Field properties for any given mix will vary due to differences in environmental/climatic factors that influence the development of binder matrix.

- Realistic characterization of these materials demands that the process must identify when acceptable properties are attained while considering practical time considerations.

- There are no specifications that will consistently require contractors to produce materials that have good engineering properties.

\subsection{EXPERAMENTAL WORK}

The experimental work described in this part was carried out as part of a larger collaboration between Carleton University and two primary road agencies in Ontario - the Ministry of Transportation of Ontario (MTO) and the City of Ottawa - that routinely use cold recycling techniques for pavement rehabilitation. Four different projects located in the area of the City of Ottawa were selected for future monitoring and loose CIR samples were transported to the laboratory to be used in the experimental work. 


\section{Proceedings of the $7^{\text {th }}$ ICCAE Conf. 27 -29 May, 2008}

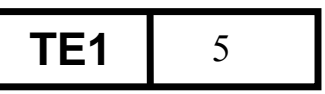

\subsection{Sample Preparation}

Base on the literature review, the best correlation of field and laboratory behaviour for CIR mixes will only be approached if the processes of laboratory mixing and compacting tend to conform to the field processes. This is principally due to the complex binder component reaction, which is primarily influenced by the environmental condition and the moisture content at that time, relative to the timing of the bituminous binder addition and any additional moisture while compacting. Specimen compaction should be in accordance with the anticipated field process. The laboratory preparation should also be undertaken within a temperature and humidity regime that also reasonably reflects field conditions as shown in Fig. 1.

The adoption of conventional "standard" compaction methods, which rely on prescribed numbers of blows of a compacting hammer or even gyratory compaction, is considered unlikely to best replicate field compaction for these types of material. Other compaction methods exist that may be more likely to achieve end results closer to field conditions, such as the vibrating table and surcharge weight, however these are generally of limited availability. A technique that may better meet this need was pioneered during the late 1960s in the UK for laboratory compaction of lean concrete. It is the use of an electric vibratory hammer fitted with a compaction foot, which was used to compact the prepared samples to assure better correlation with the field performance. Variation in density attributable to operator is expected to be minimal while using this type of compaction method. Therefore, a vibratory compactor was used as it is shown in Fig. 1.

Since the volume of the form and the required density are known, the weight to achieve the mix design density was calculated and placed in the forms as shown in Fig. 1 and then compacted using the vibratory compactor.

In order to achieve a good correlation between laboratory works and field performance the literature review explicitly insisted on simulating the field compaction, environmental conditions, timing, humidity, temperature. Therefore, the samples were prepared outside the laboratory and kept exposed to the field environmental conditions for the whole curing and testing duration.

\subsection{Testing Procedure}

As mentioned before, the laboratory testing program included:

- $\quad$ Moisture content monitoring using Time Domain Reflectometry TDR testing on a bi-daily basis.

- $\quad$ Static compression testing will be conducted every 3 days using the equipment shown in Fig. 2. 


\section{TDR: The Measurements of time domain deflectometer}

TDR is a relatively new technique to measure the moisture content for soils without disturbance $[8,9]$. Each soil has a dielectric constant, also referred to as relative electric permittivity. The dielectric constant of a soil represents the ability of this soil to store electrical potential energy, compared to vacuum, while it is under the influence of an electrical field. The TDR technique uses this ability as a base to measure the moisture content. TDR uses a cable tester to send an electric pulse via an electromagnetic transmission line into the material, with a portion of this pulse returned it reaches the end of the transmission line. The TDR unit will then measure the reflectance of the pulse with respect to time and the travel time will be a function of the dielectric constant of the soil medium as compared to bulk water [9]. The dielectric constant of free water is higher than soil and hence the value of the dielectric constant measured will be dominated by the moisture content in the natural soil (i.e. mixture of soil and water). In terms of the travel time, travel time in soil with low water content will be shorter as opposed to soil with pores filled with water. By comparing the measured value with the case of having free water or pores that have mostly air, the moisture content of the soil can be measured.

TDR measurements were collected at four to six points on each specimen to calculate the average values presented in Table 1. Fig. 6 presents the water content measured with the TDR versus time. Although there were some peaks in the middle, which were the result of rain on those specific days. However, the 8th line samples were poorly compacted, which affected their curing process (measured water content results as well as density) compared with the other samples. As it is shown in Table1, by the end of the measurements, $8^{\text {th }}$-line has water content $2.86 \%$ while Bowesville has 1.66, Russell has 1.35 and Sarsfield has 0.92 . the results mean that $8^{\text {th }}$-line samples did not cure as fast as the rest of the samples. The authors relay on the poor compaction of the $8^{\text {th }}$-line samples as the reason behind the bad curing process and this opinion was supported by measuring the specimens' densities. The results of the $8^{\text {th }}$-line project were excluded from the following tests and analysis.

\section{Static Compression Strength Test Method (SCS)}

The Static Compression Strength (SCS) test is a popular testing procedure used to examine the compression strength of concrete. However, none of the current standard test methods have investigated its ability to monitor CIR strength gain with time. During this investigation, the load was applied to the slab sample in compression along one axis up to 20 percent of the failure load while the load and corresponding displacements were recorded. The ultimate load at failure was first measured using a sacrificial sample. The selection of 20 percent of the load at failure was mainly based on practical experience and following the concept of ASTM 4123, which is used to measure the resilient modulus of asphalt pavement and suggests the use of 10 to 50 percent of the ultimate load at failure in order to complete the test without deforming the sample. The load at any moment was used to calculate the compression stress at failure as per Equation 1. 
$S C S=\frac{4 P}{\pi D^{2}}$

Where $\mathrm{P}$ is the applied load at failure $(\mathrm{N})$ and $\mathrm{D}$ is the sample diameter $(\mathrm{mm})$. Because the tested sample is subjected to compressive stresses, the test is believed to simulate the main failure mode of asphalt concrete pavements, which appears as a rut. Therefore, the test might be a good indicator of the long-term performance of the CIR pavement. The results listed in Table 2 show that the elasticity modulus was increased by three times between the 13th day and the 29th day for most of the examined mixes.

The results of the examined samples over three weeks are plotted in Fig. 4. The diagram plotted the time in days with the horizontal axis and the elastic modulus on the vertical axis. Except for 8th Line Road, the strength increased considerably for approximately 23 days, after which little additional strength was observed. From this graph, the CIR can be considered cured and the HMA overlay placed.

\subsection{Effect of Curing Time on Overlay Long-Term Performance}

Several computer programs are currently available for analyzing the pavement structure system and predicting its response and behavior. Among these programs are ILLI-PAVE, MICH-PAVE, DAMA, and KENLAYER [10]. ILLI-PAVE and MICH-PAVE are developed based on Finite Element analysis, while the other two programs are developed based on multi-layered elastic theory. In this paper, the KENLAYER computer program was adopted to calculate the pavement performance. As mentioned earlier, the main objective of this paper is to investigate the effect of curing time of CIR on the long-term performance of pavement overlay. To achieve this objective, a four-layer pavement structure is considered for this investigation. As shown in Fig. 8, the pavement structure consists of an asphalt concrete surface layer, CIR layer, a granular base, and the subgrade. A 9000-lb. single wheel load is applied at the top of the first layer. The load is represented by a 100-psi uniform pressure over a circular area with a 5.35 -inch radius. Based on the values in the literature, the Poisson's ratio, $v$, is assumed to be 0.40 for the subgrade and 0.35 for the asphalt and granular layers. The modulus of elasticity was assumed to be 500,000-psi for the surface asphalt layer, $350,000 \mathrm{psi}$ for the granular base and 10,000 for the subgrade. On the other hand, the modulus of elasticity for the CIR layer was taken from the experimental program mentioned above.

In total fifteen runs were carried out, each run was carried out at a certain modulus of elasticity. A summary of the output results of the computer software is presented in Table 3. The first column represents the mix number, the second column represents the curing time at which the modulus of elasticity was estimated, the third columns represents the modulus of elasticity, and the last columns represents the expected number of load repetitions to be carried during the pavement service life. On the other hand, Fig. 6 illustrates the relationship between the CIR curing time and the number of load repetitions which have the same trends of Fig. 4. It should be 
mentioned that the KENLAYER software estimates the number of load repetitions, which can be carried during the pavement service life, utilizing the following two equations:

$\mathrm{N}_{\mathrm{f}}=0.0796\left(\varepsilon_{\mathrm{t}}\right)^{3.291}(\mathrm{E})^{0.854}$

$\mathrm{N}_{\mathrm{d}}=1.365^{*} 10^{-9}\left(\varepsilon_{\mathrm{c}}\right)^{4.477}$

Where

$\mathrm{N}_{\mathrm{f}}=$ number of load repetitions to prevent fatigue cracking.

$\mathrm{N}_{\mathrm{d}}=$ number of load repetitions to limit permanent deformation.

$\varepsilon_{\mathrm{t}}=$ the tensile strain at the bottom of the asphalt layer.

$\varepsilon_{\mathrm{c}}=$ the compressive strain at the top of the subgrade.

$\mathrm{E}=$ modulus of elasticity of the asphalt layer in psi.

Based on the output results of KENLAYER illustrated in Table 3 and Fig. 9, the following remarks can be drawn:

- The curing time of CIR plays a significant role in the life cycle of the asphalt pavement structure.

- By increasing the curing time of CIR the service life of the pavement structure increases.

- The increasing rate of number of allowable load repetitions decreases with time.

- The increasing number of allowable load repetitions versus curing time is not constant for all mix types.

\subsection{SUMMARY AND CONCLUSIONS}

The objective of this project was set to investigate the effect of the CIR curing time on the behaviour of asphalt concrete pavement

Based on the recommendations of the literature review, an experimental program was conducted to investigate the changes in mechanical properties of the CIR with time. To better simulate the field construction process, a vibratory compactor was utilized to prepare slab samples from four different Cold In-place Recycled (CIR) mixes used in four different projects. The static compression strength test was then used to measure the mechanical properties (modulus of elasticity), while Time Domain Reflectometry (TDR) was used to measure the water content. Finally an analytical analysis was carried out to investigate the effect of the curing time of CIR on the life cycle of asphalt concrete pavement. The following conclusions were drawn from the study:

- The TDR is a good tool to measure the change in the water content of CIR specimens with time.

- The static compression test method was capable of capturing the change in modulus of elasticity with time and therefore can be considered a suitable test for monitoring the curing 


\section{Proceedings of the $7^{\text {th }}$ ICCAE Conf. 27 -29 May, 2008}

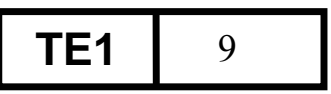

of CIR. By observing the change in elastic modulus with time, the point at which further strength gain of the CIR mix was also observed and signalled when the Hot Mix Asphalt (HMA) overlay could be laid.

- The Analytical Investigation shows that the selection of the right time for the CIR to be covered with a hot asphalt mix is a critical factor that can affect the long-term performance of asphalt concrete pavement to a large extent.

- It is recommended for future works is to have a family of standard curves that can be used to predict the modulus of the elasticity of CIR as a function of the curing time and the main properties of CIR mixes.

\section{REFERENCES}

1. Lauter, K. "Field and Laboratory Investigation of the Effect of Cold In-Place Recycled Asphalt on Transverse Cracking", Carleton University M. Eng. Thesis (1998).

2. Emery, J.J. , J.A. Gurowka, T. Hiramine, “Asphalt Technology for In-Place Surface Recycling Heat Reforming Process", Proceedings RTAC Conference, Halifax (1988).

3. Jahren, C. T., B. J. Ellsworth, B. Cawley and K. Bergeson, "Cold In-Place Recycled Asphalt Concrete Project". HR 392, for Iowa Department of Transportation Project Development Division and the Iowa Highway Research Board, February (1998).

4. Rogge, D.F., R.B. Lehey, and R. Blair. "Cold In-Place Recycling (CIR) With Lime." Transportation Research Report: 95-17, Transportation Research Institute, Oregon State University, Corvallis, (1996).

5. Epps, J. A. "Cold Recycling Bituminous Concrete Using Bituminous Materials". NCHRP synthesis of highway practice 160, Transportation Research Board, Washington, D.C., July 1990.

6. Lee, K.W., T. E. Brayton, and M. Huston, "Development of Performance Based Mix-Design for Cold In-Place Recycling (CIR) of Bituminous Pavements Based on Fundamental Properties". FHWA- URI-CVET-02-1, September 2002.

7. Lane, B., and Tom Kazmierowski "Implementation of Cold In-Place Recycling with Expanded Asphalt Technology in Canada" Transportation Research Board, Washington, D.C., Jan (2005).

8. Mostafa, A. "The Stripping Susceptibility of Airfield Asphalt Mixes: The Development of Guidelines for a Laboratory Test Method" Carleton University, Ph.D. thesis, Ottawa, Ontario, (2005).

9. Topp, G.C., J.L. Davis and A.P. Annan, "Electromagnetic Detection of Soil Water Content: Measurements in Coaxial Transmission Lines". Water Resource Research. Vol. 16, No. 3, P. 574-582, (1980).

10. Huang, Y.H. 2003. "Pavement Analysis and Design", Prentice-Hall, Inc., New Jersey, USA. 


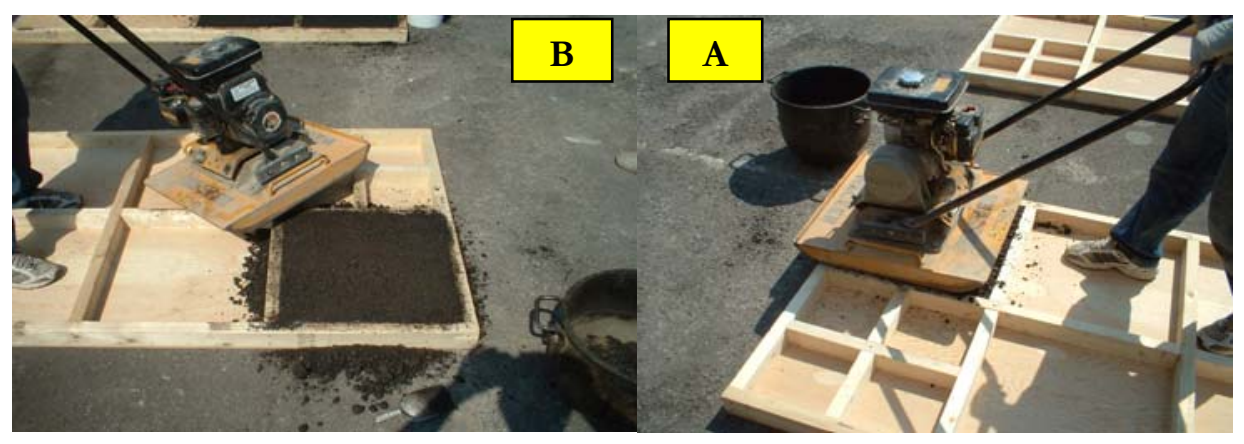

Fig. 1. Sample compaction in forms

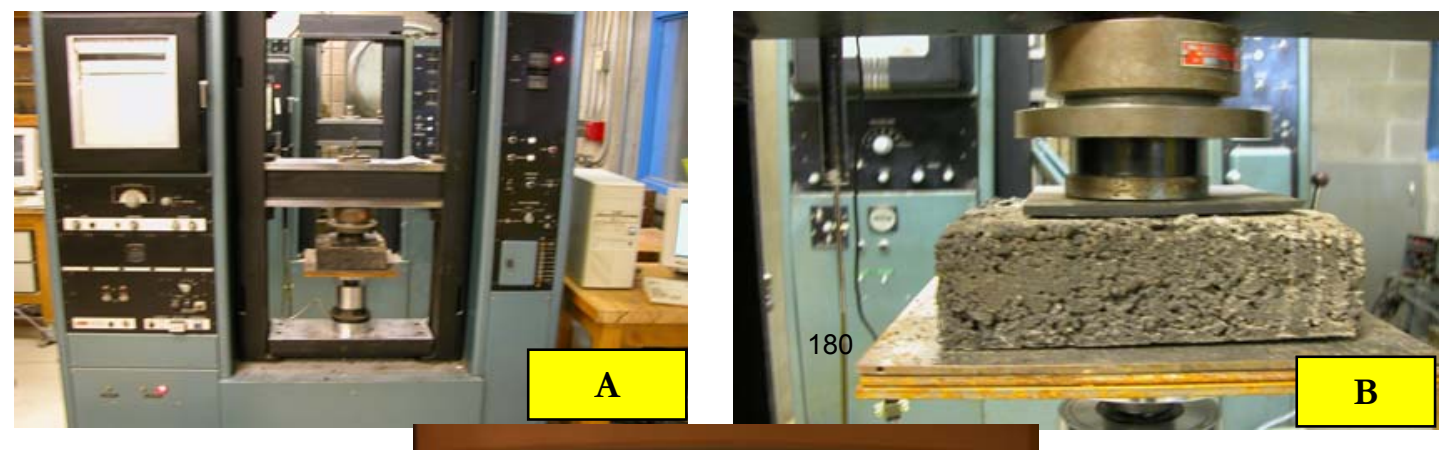


Fig. 2. Procedure and instruments of the static compression test 


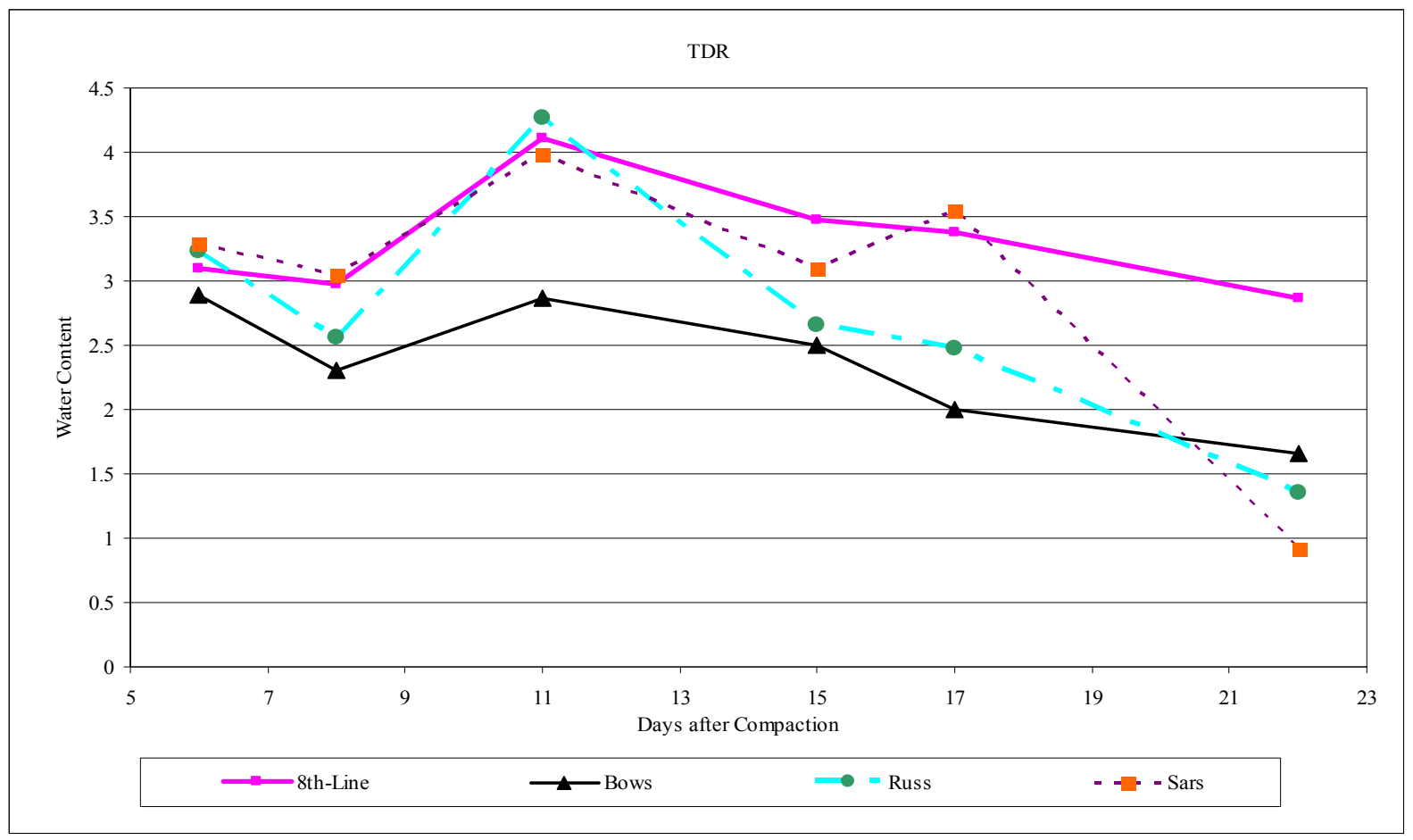

Fig. 3. Plot of water content with time using time domain reflectometry

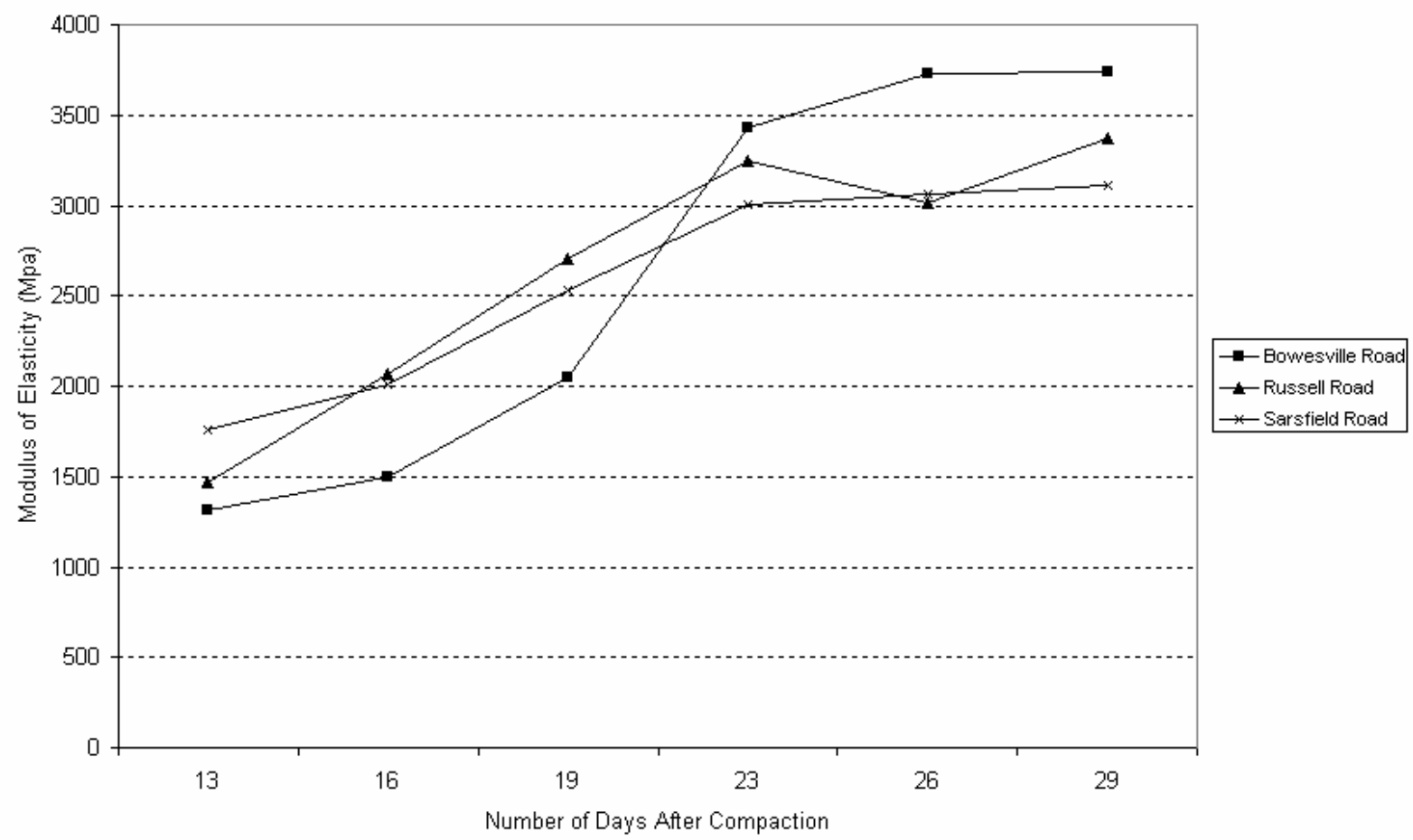


Fig. 4. Modulus of Elasticity versus Time

\begin{tabular}{|c|c|}
\hline & 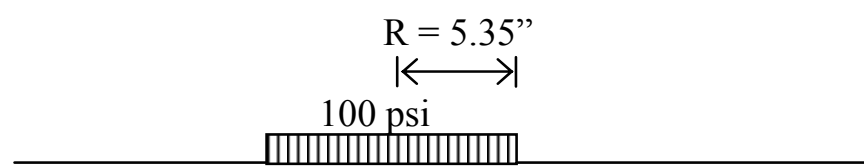 \\
\hline $\mathrm{AC}$ & Poisson's ratio $=0.35$, Thickness $=4 ", E=500,000$ psi \\
\hline CIR & Poisson's ratio $=0.35$, Thickness $=4 ", E=$ Variable \\
\hline
\end{tabular}

Base Poisson's ratio $=0.35$, Thickness $=10^{\prime \prime}, \mathrm{E}=30,000 \mathrm{psi}$

1 psi $=6.89 \mathrm{kPa}$; inch $=2.54 \mathrm{~cm}$

Subgrade

$$
\text { Poisson's ratio }=0.40, \mathrm{E}=10,000 \mathrm{psi}
$$

Fig..5. Pavement structure system

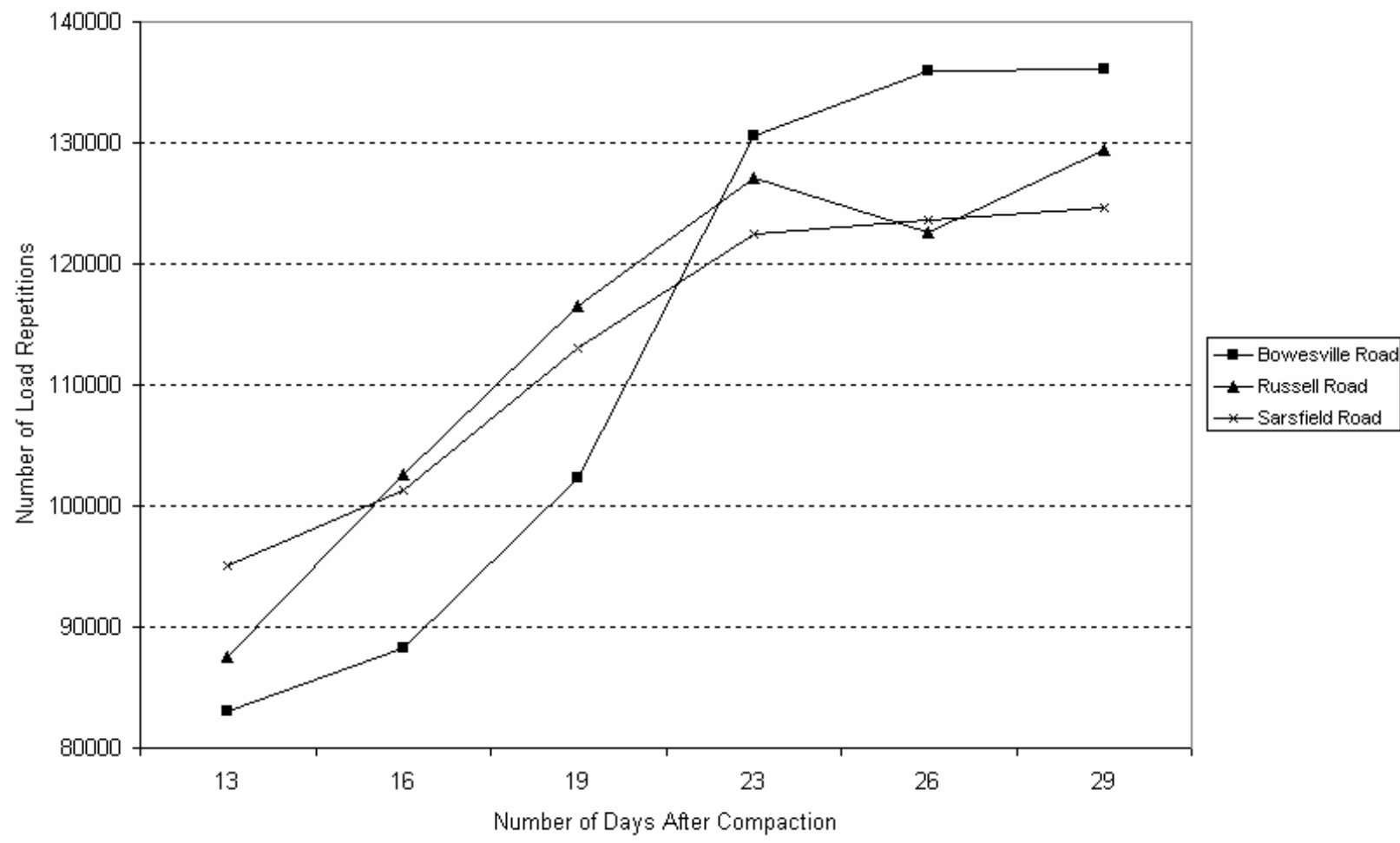


Fig. 6. Curing time versus number of load repetitions

Table 1. Average TDR water content for recycled mixes with time

\begin{tabular}{|c|c|c|c|c|}
\hline \multirow{2}{*}{$\begin{array}{c}\text { Number of days after } \\
\text { compaction }\end{array}$} & \multicolumn{4}{|c|}{ Water Content (\%) } \\
\cline { 2 - 5 } & $\begin{array}{c}8^{\text {th }} \text { Line Road } \\
\text { Mix 1 }\end{array}$ & $\begin{array}{c}\text { Bowesville Road } \\
\text { Mix2 }\end{array}$ & $\begin{array}{c}\text { Russell Road } \\
\text { Mix3 }\end{array}$ & $\begin{array}{c}\text { Sarsfield Road } \\
\text { Mix4 }\end{array}$ \\
\hline 6 & 3.1 & 2.89 & 3.23 & 3.29 \\
\hline 8 & 2.97 & 2.31 & 2.56 & 3.05 \\
\hline 15 & 3.47 & 2.5 & 2.66 & 3.1 \\
\hline 17 & 3.38 & 2 & 2.48 & 3.55 \\
\hline 22 & 2.86 & 1.66 & 1.35 & 0.92 \\
\hline
\end{tabular}

Table 2. Results of static compression testing of recycled mixes

\begin{tabular}{|c|c|c|c|c|}
\hline \multirow{2}{*}{$\begin{array}{l}\text { Number of days } \\
\text { after compaction }\end{array}$} & \multicolumn{4}{|c|}{ Modulus of Elasticity (MPa) } \\
\hline & $\begin{array}{c}8^{\text {th }} \text { Line Road } \\
\text { Mix } 1\end{array}$ & $\begin{array}{c}\text { Bowesville Road } \\
\text { Mix2 }\end{array}$ & $\begin{array}{c}\text { Russell Road } \\
\text { Mix3 }\end{array}$ & $\begin{array}{l}\text { Sarsfield Road } \\
\text { Mix4 }\end{array}$ \\
\hline 13 & 1124.75 & 1311.31 & 1468.95 & 1757.88 \\
\hline 16 & 1347.82 & 1497.16 & 2063.96 & 2009.8 \\
\hline 19 & 1451.06 & 2052.85 & 2702.29 & 2535.07 \\
\hline 23 & 1718.81 & 3433.76 & 3245.6 & 3000.75 \\
\hline 26 & 2428.89 & 3730.80 & 3010.90 & 3060.50 \\
\hline 29 & 3433.16 & 3739.93 & 3368.30 & 3114.11 \\
\hline
\end{tabular}


Table 3. Effect of curing time on long-term performance

\begin{tabular}{|c|c|c|c|c|}
\hline Mix Number and Location & $\begin{array}{c}\text { Number of days } \\
\text { after compaction } \\
13\end{array}$ & $\begin{array}{c}\text { Modulus of } \\
\text { Elasticity (MPa) } \\
1311.31\end{array}$ & $\begin{array}{c}\text { Number of } \\
\text { Load } \\
\text { Repetitions } \\
83006\end{array}$ & $\begin{array}{c}\% \text { of } \\
\text { Number of } \\
\text { Load } \\
\text { Repetitions } \\
0\end{array}$ \\
\hline \multirow{5}{*}{$\begin{array}{c}\text { Bowesville Road } \\
\text { Mix2 }\end{array}$} & 16 & 1497.16 & 88266 & 6.3 \\
\hline & 19 & 2052.85 & 102310 & 23.3 \\
\hline & 23 & 3433.76 & 130630 & 57.4 \\
\hline & 26 & 3730.80 & 135920 & 63.7 \\
\hline & 29 & 3739.93 & 136080 & 63.9 \\
\hline \multirow{6}{*}{$\begin{array}{l}\text { Russell Road } \\
\text { Mix3 }\end{array}$} & 13 & 1468.95 & 87489 & 0 \\
\hline & 16 & 2063.96 & 102580 & 17.2 \\
\hline & 19 & 2702.29 & 116520 & 33.2 \\
\hline & 23 & 3245.6 & 127160 & 45.3 \\
\hline & 26 & 3010.90 & 122680 & 40.2 \\
\hline & 29 & 3368.30 & 129430 & 47.9 \\
\hline \multirow{6}{*}{$\begin{array}{l}\text { Sarsfield Road } \\
\text { Mix4 }\end{array}$} & 13 & 1757.88 & 95122 & 0 \\
\hline & 16 & 2009.8 & 101300 & 6.5 \\
\hline & 19 & 2535.07 & 113040 & 18.8 \\
\hline & 23 & 3000.75 & 122480 & 28.8 \\
\hline & 26 & 3060.50 & 123640 & 30.0 \\
\hline & 29 & 3114.11 & 124670 & 31.1 \\
\hline
\end{tabular}

